\title{
Developing Monitoring System for Solar Water Pump based on Wireless Sensor Network in Grigak Beach, Yogyakarta, Indonesia
}

\author{
A.B.Primawan ${ }^{1}$, W.Widyastuti ${ }^{2}$, D.Widjaja ${ }^{3}$ Iswanjono $^{4}$ \\ \#Electrical Engineering Department, Sanata Dharma University Yogyakarta \\ Kampus III USD, Paingan, Maguwoharjo, Sleman, Yogyakarta 55281, Indonesia
}

\begin{abstract}
The Solar Water Pump is the solution to the provision of raw water for the community, especially the residents of Girikerta, Panggang, Gunung Kidul. Raw water sources at Grigak Beach have been able to be lifted and distributed to residents. The location of each water reservoir is located so far apart that it needs to be monitored in order to maintain the system. Wireless Sensor Network (WSN) system is an alternative solution for monitoring and maintenance. The study to design and implement a WSN is needed to carry out monitoring in the context of maintenance of the pump system, both located in water sources and water reservoirs. The resulting monitoring system consists of a series of sensor nodes and a sensor gateway circuit. Sensor nodes consist of temperature sensors, $R F$ transmitter devices and microcontrollers. Meanwhile the sensor gateway consists of temperature sensors, $R F$ transmitter devices, cellular devices and microcontrollers. The measurement results are then sent to the cloud server to be displayed and accessed by the public. The results of testing this monitoring system indicate that the system has functioned according to the design.
\end{abstract}

Keywords - monitoring system, wireless sensor network, solar water pump system.

\section{INTRODUCTION}

Grigak Beach in Girisobo, Panggang, Gunung Kidul is a coastal area that has underground river water sources. The potential of water resources in the form of underground rivers to date has not been explored optimally. At present a solar water pump (SWP) has been installed to collect water and distribute it to surrounding residents.

The SWP installation project location can be seen in Figure 1. The location of the pump installation and water reservoir as part of the water distribution is approximately 2 (two) kilometers divided into four parts. The location of each part is: the location of the water pump, the location of the first water reservoir, the location of the second water reservoir and the location of the last water reservoir. The location of the water pump is located on the beach, while the location of the last water reservoir is located in the community shelter. While the location of the first and second water reservoirs are located between the coast and the settlement.

Installation of clean water lifts that are currently being built are based on the power supply provided by solar panels[1]. Although this installation system maintenance as a whole is very easy to do, access to the installation is still quite difficult. The terrain is hilly and road condition that are still not good cause maintenance difficult. The responsibility of caring for this installation will later be on the side of the community. The community has also been given sufficient knowledge to be able to care for their selves.

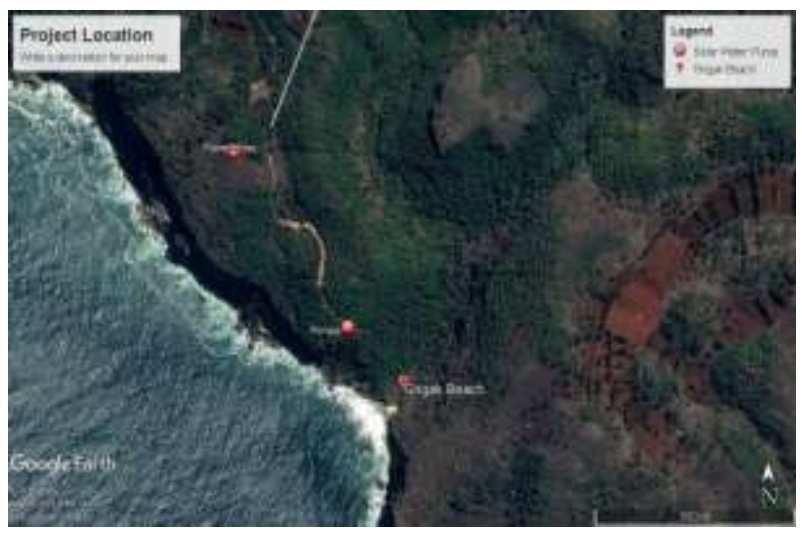

Fig 1: Solar Water Pump System Location at Grigak Beach

However, more than that, the technical team that conducts the installation will be better able to provide support at any time if problems arise in the installation with additional communication access and reliable data transmission to monitor remotely. In monitoring this water removal installation, various sensors from solar panels, water pumps, water tank, etc. must be properly installed. These various sensors will produce data that can be 
accessed directly by users via the internet network. A real time monitoring mechanism such as this will provide an opportunity for the technical team to find out about installation problems as soon as possible and provide advice and follow-up to the community as well. Implementation of sensor network technology is expected to overcome this problem. Sensor network technology has been carried out in the field of environment by [2] and [3]. The results of utilizing the wireless sensor network are good enough to carry out the monitoring process. Therefore, a monitoring system that is reliable, inexpensive and easy to use becomes a necessity[4].

Telemetry systems with GSM communication are also used in early warning systems and tracking on motorcycle vehicles, temperature telemetry, vehicle tracking systems, telemetry systems solar fuel volume monitoring on BTS, telemetry monitoring river water level [2]. To guarantee communication can be applied to an object oriented design system development system the use of GSM communication is also developed, so it can be implemented on computer systems[5] .

This research aims to produce a real time water pump device performance monitoring system based on the Wireless Sensor Network. The benefits of this research are to help in maintaining and monitoring of Solar Water Pump installations devices.

\section{MATERIAL AND METHOD}

(he development of wireless sensor network technology has become increasingly rapid nowadays. The wireless sensor network is basically a combination of sensor technology and communication technology. As shown in Figure 2, sensor technology is developed as a basis for monitoring systems. The monitoring system is divided into three main parts, namely: server (master) devices, sensor devices and actuators and communication devices.

The server device is in charge of controlling the entire process of monitoring and controlling the system. While the sensor and actuator device is assigned to provide input data and output data for the server device. The communication device is in charge of sending data between the server / master device and sensor devices and actuators. This basic concept applies generally in sensor network systems[6].

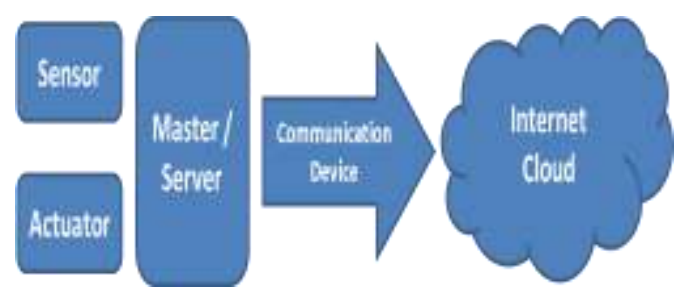

Fig 2: Sensor Network in Monitoring System
Arduino technology was used to develop the sensor network wirelessly[7]. This minimum system combined Arduino Uno micropocessor, DHT11 sensor device, NRF24LI of radio communication device and SIM900 for cellular communication.

The programming algorithms designed on sensor devices and servers on the sensor network can be seen in Figure 3. In the flow chart, the process of measuring and processing data begins with time synchronization between sensors and servers. Then the sensor measurement results will be sent to the server both at the location of the first water reservoir (sensor 1) and the location of the third water reservoir (sensor 2). Meanwhile the server device is located in the second water storage location. The gateway then sent data to the database using the internet network. An application will be created to read data from the database.

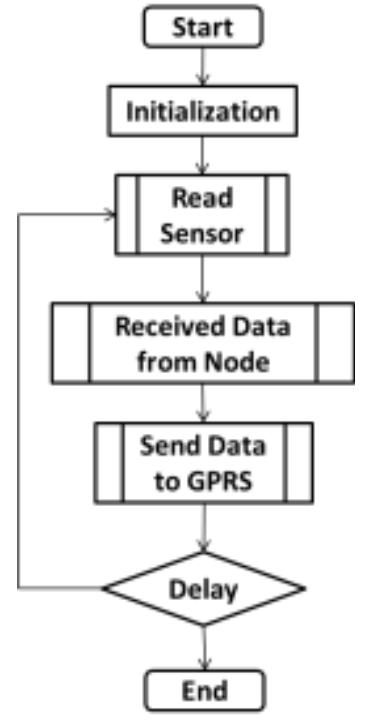

(a) Gateway Sensor

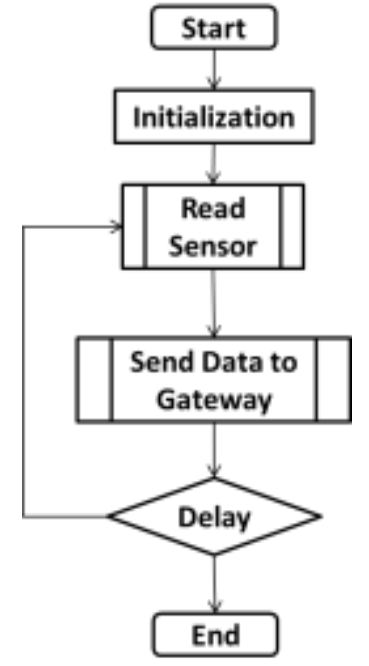

(b) Node Sensor
Fig 3: Gateway and Node Sensor Diagram

\section{RESULT AND DISCUSSION}

All The wireless sensor circuit prototype that has been implemented consists of a se gateway circuit module and a sensor node circuit module (see Fig.4 ). The server module is responsible for receiving measurement data from each sensor node and at the same time as a gateway to the internet network. Cloud Server of Thingspeak is used as a viewer of temperature and humidity data that can be accessed by the public via the internet network. 


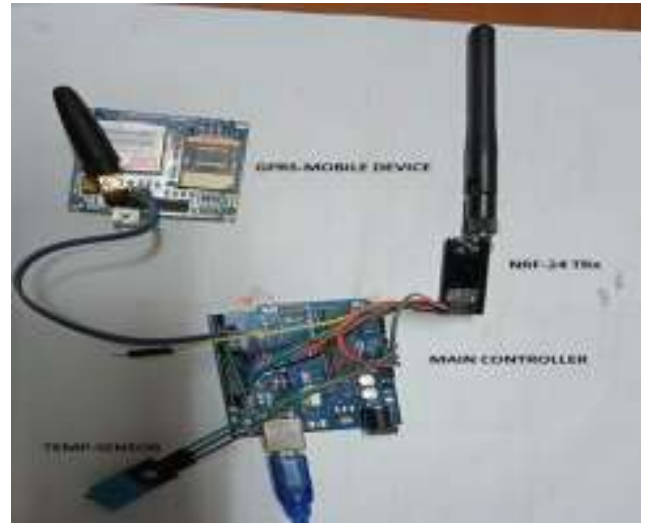

Fig 4: Wireless Sensor Prototype

The results of testing data transmission in the radio transmission process using the NRRF24 module are presented in Fig. 5, in general the data transmission process can be carried out according to the design. However, the characteristics of the air transmission media cause several errors during data transmission. Transmission errors for this design are not re-transmitted method. So the results used are the last results received by the recipient, in this case the gateway series. This monitoring system does not require correction of transmission data, so anything sent will be stored and displayed by the system.

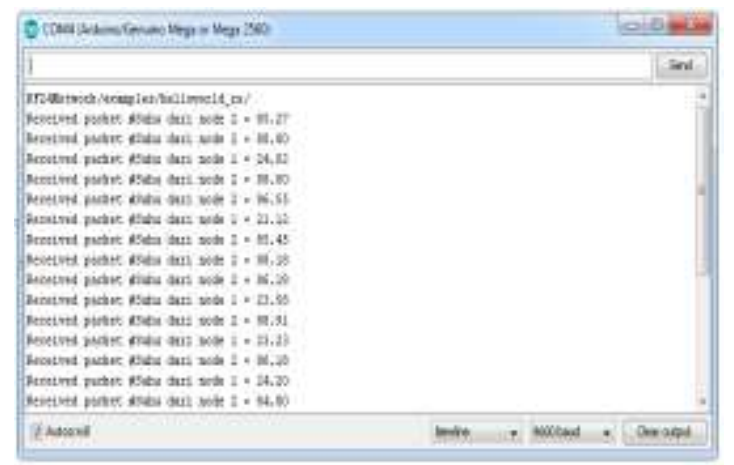

Fig 5: Gateway and Node Sensor Data Acquisition

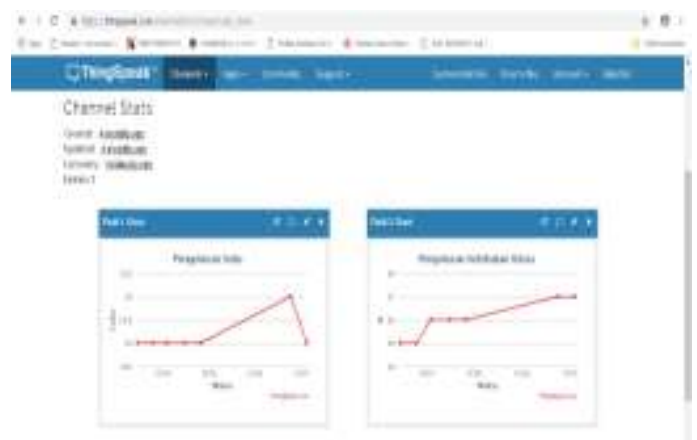

Fig 6: Gateway and Node Sensor Monitoring Display with Thingspeak
Meanwhile the connection process and data transmission from the gateway to the cloud server via GPRS network has been successful implemented. From the observations, the data transmission process using the AT-Command function can be implemented properly. This does not appear to be an error during the process of connection and data transmission.

The final result of this monitoring system is the display of data measurement data from sensors on a cloud server page that can be accessed by the public (Fig.6). A connection mechanism was established from the gateway to the cloud server, while the mechanism for connecting and sending data is done firstly to initialize the GPRS data network, and then connect to the cloud server that matches the ID number of the database used.

The test results of temperature measurement and data transmission are presented in Fig.7. The measurement data of the DHT11 temperature sensor compared to the temperature data of the Fluke17 sensor shows that there are differences in measurement results, although not too significant. Meanwhile, the display on the cloud server shows some data experiencing errors during the sending process via the GPRS network.

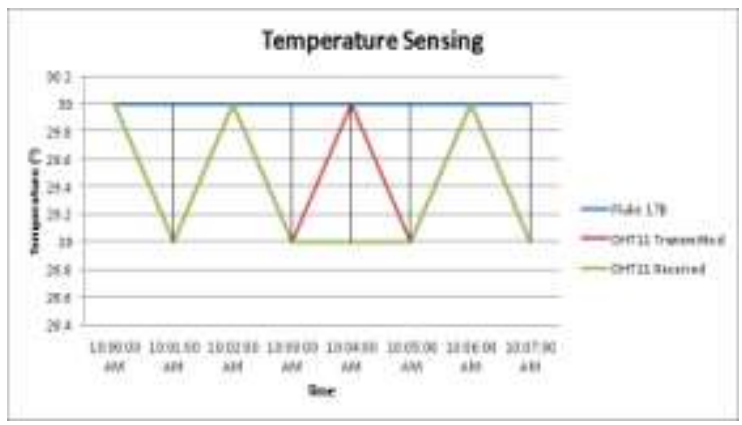

Fig 7: Comparison of Data Sensor

The power produced by solar cell is measured daily as energy production during the day is still able to produce energy. The results of monitoring (monitoring) through GPRS telemetry from September to November 2019 is shown in Fig. 8.

The energy produced during September is 623 $\mathrm{kWH}$, in October 2019 is $606 \mathrm{kWH}$, and November 2019 (until November 24) is $415 \mathrm{kWH}$. The average energy acquisition per day in September 2019 is 21 $\mathrm{kWH}$, month October 2019 is $20 \mathrm{kWH}$, and November 2019 is $17 \mathrm{kWH}$. Average power the resulting solar cell obtained was 3,356 watts (69.92\%) in September 2019, 3,232 watts (67.33\%) in October 2019, and in November 2019 it was 2943 watts $(61.32 \%)$.

In November 2019 it was shown that the average energy, voltage, and the flow has decreased because the weather is already cloudy. This is certainly has been affected by intensity of sunlight that can be 
accepted by solar panels to be changed into electrical energy.

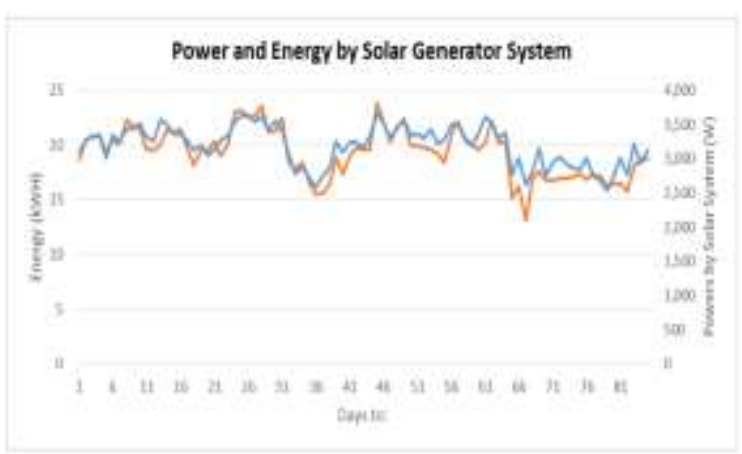

Fig 8: Energy and Power production of Solar Panel.

\section{CONCLUSIONS}

The monitoring system based on wireless sensor network consists of Sensor Node Series and Sensor Gateway Series. The test results show the system has been able to work in accordance with the designed. Data transmission between sensors uses an RF transmitter while an internet connection uses GPRS cellular networks. The test results for sending data have been successful even though an error still occurred, so that it will be returned for improvement. Moreover, the monitoring results are displayed through the internet network on a predetermined cloud server.

\section{ACKNOWLEDGMENT}

We would like to thank Center of Research and Community Services (Lembaga Penelitian dan Pengabdian Masyarakat) of Sanata Dharma Univesity for providing research grant.

\section{REFERENCES}

[1] S. S. Chandel, M. Nagaraju Naik, and R. Chandel, "Review of solar photovoltaic water pumping system technology for irrigation and community drinking water supplies," Renewable and Sustainable Energy Reviews. 2015.

[2] A. Faustine, A. N. Mvuma, H. J. Mongi, M. C. Gabriel, A. J. Tenge, and S. B. Kucel, "Wireless Sensor Networks for Water Quality Monitoring and Control within Lake Victoria Basin: Prototype Development," Wirel. Sens. Netw., vol. 6, pp. 281-290, 2014.

[3] S. Ferdoush and X. Li, "Wireless sensor network system design using Raspberry Pi and Arduino for environmental monitoring applications," Procedia Comput. Sci., vol. 34, pp. 103-110, 2014.

[4] K. C. Sanagavarapu, "A Review on Green Wireless Sensor Network Technology And Big Data Analytics Towards Iot," Int. J. Comput. Trends Technol., vol. 67, no. 6, pp. 121-126, 2019.

[5] T. Hartalkar Suyog Bhore Ketki Borawake Shraddha Naik, "GSM based Home Automation using MQTT," Inte rnational J. Eng. Technol. Ms. Tejal Hartalkar, Mr. Suyog Bhore, Ms. Ketki Borawake, 2015.

[6] C. Bell, Beginning Sensor Networks with Arduino and Raspberry Pi. Berkeley, CA: Apress, 2013.

[7] J. P. M and P. S. S, "Wireless Temperature detector System using ARDUINO and IOT," Int. J. Comput. Trends Technol., vol. 67, no. 11, pp. 82-83, 2019. 